\title{
Establishment of rainfall Intensity-Duration-Frequency Equations and Curves used to design an appropriate and sustainable hydraulic structure for controlling flood in Nyabugogo catchment-Rwanda.
}

Jean Claude Nizeyimana ${ }^{1}$, Shanshan Lin ${ }^{1}{ }^{\text {* }}$, Fabrice Ndayisenga ${ }^{2}$, Gratien Twagirayezu ${ }^{3}$, Junaid Khan ${ }^{1}$, Phyoe Marnn${ }^{1}$, Dawuda Usman Kaku¹, Bazel Musaed Abdullah Al-Shaibah', Ali Rajeh Hussein Ahmed Al-aizari ${ }^{1}$, Yousef Ahmed Ali Ahmed Al-Masnay ${ }^{1}$ and Olivier Irumva ${ }^{4}$

* Corresponding author (Lin Shanshan)

E-mail: $\underline{\text { linss071@nenu.edu.cn }}$

Phone number: +8613321583738

Mailing address: School of Environment, Northeast Normal University, Changchun, 130117china. 


\section{Affiliation of the authors}

Jean Claude Nizeyimana ${ }^{1}$, Shanshan Lin ${ }^{1, ~ *}$, Fabrice Ndayisenga ${ }^{2}$, Gratien Twagirayezu ${ }^{3}$, Junaid Khan', Phyoe Marnn', Dawuda Usman Kaku , Bazel Musaed Abdullah Al-Shaibah', Ali Rajeh Hussein Ahmed Al-aizari ${ }^{1}$, Yousef Ahmed Ali Ahmed Al-Masnay ${ }^{1}$ and Olivier Irumva 4

Mailing address:

${ }^{1}$ School of Environment, Northeast Normal University, Changchun, 130117, China.

${ }^{2}$ College of Resources and Environment, University of Chinese Academy of Sciences, Beijing 100049, China.

${ }^{3}$ School of Environmental and Municipal Engineering, Lanzhou Jiaotong University, Lanzhou, 730070, China

${ }^{4}$ School of Eco-Environmental Engineering, Guizhou Minzu University, Guiyang, Guizhou Province 550025, PR China

E-mail: nizeyeclaude570@gmail.com(J.C.Nizeyimana); linss071@nenu.edu.cn (L. Shanshan); fabnd50@yahoo.fr(F.Ndayisenga);tgratien0@gmail.com(G.Twagirayezu);junaideco@,outlook.co m (J.Khan). zawminhtetphyoemarnn@gmail.com (Phyoe Marnn); usmandawuda@yahoo.com (U.K. Dawuda); alshaibah123@gmail.com(M.AA.Bazel); alialaizari1992@gmail.com(A. Ali) and yousefmasnay@gmail.com (A.A.M. Yousef). 


\section{Author contributions}

Altogether authors contributed to the study conception and design

Conceptualization and writing - original draft preparation [Jean Claude Nizeyimana], Supervision and Resources [Shanshan Lin],

Formal analysis and investigation [Fabrice Ndayisenga], [Gratien Twagirayezu], [Olivier Irumva] and [Phyoe Marnn],

Writing - review and editing [Junaid Khan] and [Bazel Musaed Abdullah Al-Shaibah] and

Data collection [Dawuda Usman Kaku], [Ali Rajeh Hussein Ahmed Al-aizari] and [Yousef Ahmed Ali Ahmed Al-Masnay].

All authors read and approved the final manuscript 


\begin{abstract}
Intensity Duration Frequency curves describe the connection between rainfall intensity, rainfall duration and return period. Intensity-Duration-Frequency (IDF) curves are one of the most often applied implements in water resource engineering in areas aimed at controlling floods. In particular, IDF curves for precipitation answer problems of improper drainage systems or conditions and extreme characters of precipitation which are the main cause of floods in Nyabugogo catchment. This study aims to establish Rainfall IDF empirical equations, curves and predicted peak rate of runoff $\left(\mathrm{Q}_{\log y}\right)$ equations that will be used for designing appropriate and sustainable hydraulic structures for controlling flood in Nyabugogo catchment. Goodness of Fit tests revealed that Gumbel's Extreme-Value Distribution method appears to have the most appropriate fit compared with Pearson type III distribution for validating the Intensity-DurationFrequency curves and equations through the use of daily annual for each meteorological station. The findings of the study show that the intensity of rainfall increases with a decrease in rainfall duration. Additionally, a rainfall of every known duration will have a higher intensity if its return period is high, while the predicted peak rate of runoff $\left(\mathrm{Q}_{\operatorname{logy}}\right)$ increases also with an increase in the intensity of rainfall.
\end{abstract}

Keywords: Adequate drainage structures; Rainfall IDF Curve relationship; predicted peak rate of runoff (Q $\left.Q_{\operatorname{logy}}\right)$; Gumbel's Extreme Value Distribution Method. 


\section{INTRODUCTION}

Due to the increase in the emission of greenhouse gases, the hydrologic cycle is being altered on the daily basis. Rainfall is noticed to be one of the major determining factors in the hydrological cycle. When an area receives rainfall, the efflux of water at that area is known as stormwater. The categorization of a storm is mainly based on its Intensity, Duration and Frequency. Besides the occurrence of continuous heat, variations in extreme meteorological events such as cold waves, heavy rainfall and drought are results of modifications in climate. Modifications in the hydrological cycle owing to an increase in greenhouse gases lead to changes in the IDF of rainfall events. Curbing the adverse effects associated with climate change and adapting to them a technique to control some of the urban risk factors. As the result of the rainfall used in hydraulic design, assessment and updating of rainfall characteristics (mean: Intensity- Duration- Frequency (IDF) curves in the future are needed [1]. Intensity-Duration-Frequency relationship is a mathematical interconnection between rainfall intensity I, the duration $\mathrm{d}$, and the return period $\mathrm{T}$ (similarly, the annual frequency of exceedance, typically denoted to as 'Frequency' only) [2].

Rwanda is a country which is located in one of the tropical regions of the earth. As projected by Engineers, it is challenging to construct Intensity-Duration-Frequency curves for rainfall in the above climatic region due to the lack of long-term extreme rainfall data. Careful planning is adopted in making an amalgamation of limited high-frequency information on rainfall maximum values with long-run daily data of rainfall. We should note due to climate change, precipitation increases at an alarming rate and that sudden increase in rainfall is the primary cause of flooding. Flood is known to be one of the ultimate natural disasters that affect people's health as well as the economies worldwide. As it relates to Rwanda, due to climatic profile and its relief (geographical features), Rwanda is among countries that are at risk of natural disasters in sub- Sahara Africa, 
most especially localized floods [3].

Rwanda experiences disasters such as landslides and flooding due to extreme rainfall. In those cases, lives and properties are lost due to erosion and other forms of environmental deprivation which are prevalent in the country. This problem has increased due to the poor management of high discharging runoffs which has provoked hydrological risks especially in urban areas [4].

Nyabugogo catchment is considered among the catchments in Rwanda, where Kigali, the most populous city is located. Flood-related disasters are often reported in this catchment. This is mainly owing to its altitude which is low compared to other neighboring areas and its nature of the convergence zone of drainage systems especially in Kigali city which has been repetitively subjected to floods. Floods can occur when water accumulates above the soil surface (e.g. from rainfall) and cannot flow quickly [5] and also they are most likely to happen in city areas which have fast runoff processes and short response times because of a greater dominance of impermeable surfaces [6]. Flood damages property and endangers the lives of humans and other species. Moreover, its rapid water runoff causes simultaneous sediment deposition elsewhere and soil erosion (for instance: downstream). Also, the breeding grounds for fish and other wildlife habitats can be destroyed [7-10]. Floods in Nyabugogo usually cause adverse effects that can be classified as follows: Primary effects: Physical destruction which can affect any type of structure including roadways, cars, houses, canals, bridges, and sewerage systems [11]; secondary effects: polluted water supplies, flooded farmland, destruction of vegetation, impede transportation; and Tertiary and long-term economic effects [12].

Intensive flooding which occurs in the Nyabugogo River can be categorized as flash floods which generally result from intensity rainfall even over a relatively small area or if the area was before saturated from the last precipitation. Since the 2013 flood has been disturbing Nyabugogo 
wetland and has resulted in the loss of four human lives who got drawn in a car due to the flood, loss of properties and animal health and disturbance of socio-economic activities, disturbance of businesses in the region. Also, issues such as transport facilitation at times come to a halt because of flooding in the wetland during the rainy season [13]. For instance, stormy weather from $02^{\text {nd }}$ to $03^{\text {rd }}$ February 2020 brought thunderstorms and floodwaters that caused floods and landslides in the capital, Kigali, and other parts of the country. Referring to the ministry's provisional update of $03^{\text {rd }}$ February, at least thirteen people died, two people injured and fifteen houses destroyed in Jali in Gasabo District including twelve households were damaged in Nyarugenge District. (http://floodlist.com/africa/rwanda-floods-landslides-february-2020).

Potential loss of life, degradation of water, air and soil quality and property damage due to flooding is caused by extreme rainfall events [14]. The major cause of the flood is rainfall runoff that cannot be channeled appropriately into the drainage systems forcing the water to flow overland. Clogged or lack of proper drainage system is usually the cause of this type of flooding [15]. Ancient rainfall events are used to design structures mostly hydraulic structures as well as many other flood protection structures relating to hydrologic flows [16].

Previous studies have been established to investigate and assess factors affecting adaptation, the mitigation of climate change and to increase and sharpen the disaster controlling by various stakeholders $[17,18]$; but no study has assessed the question of waterlogging and flood which are a common problem during the raining period due to poor living condition of people and inadequate drainage system. To address this problem, a new drainage design with hydraulic discharge ( $\left.\mathbf{Q}_{\text {lics }}\right)$ should be designed that should be higher than the predicted peak rate of runoff (predicted hydrological discharge (Q $\mathbf{l o g y})[19,20]$. 
This research was conducted to establish IDF Curves and equations for various duration of rainfall in eight Districts which are Nyarugenge, Gasabo, Kicukiro, Rulindo, Gicumbi, Rwamagana, Kayonza and Gatsibo with their meteorological stations such as Gitega, Kabuye sugar, Kigali Aero, Rulindo, Byumba Pref., Rwamagana, Kayonza and Kiziguro respectively of Nyabugogo catchment. In this present research, Gumbel's Extreme value Distribution method (GEVDM) is applied to develop IDF curves and equations. In this background, a trial has been made to develop the precipitation for the different return periods and different durations of ' $\mathrm{n}$ ' such as $10,20,30,60,120,180,360,720$ and 1440 min adopting GEVDM for generation of IDF relationship with eight Districts of Nyabugogo catchment-Rwanda [21, 22].

Model performance indicators such as correlation coefficient $(\mathrm{R})$ is used to examine the performance of the established Intensity-Duration-Frequency relationships by GEVDM for the design of rainfall intensity for the areas under study. Rainfall is normally calculated using Intensity-duration-frequency (IDF) Curves [23]. This study aims to establish Rainfall IDF empirical equations, curves, and hydrological discharge equation for eight Districts that will be used for designing an appropriate and sustainable hydraulic structure for controlling flood to reduce human and economic losses and improve infrastructure planning and design in Nyabugogo catchment. This study will help to design hydraulic structures for a long period especially in this study area of Nyabugogo catchment. The information generated can be used for water resource projects, sewer systems design, or water quality management projects in large urban areas such as Kigali [24]

\section{DATA COLLECTION AND METHODOLOGY}

\subsection{Description of the Study Area}


Nyabugogo catchment is located in the central-eastern part of Rwanda and consists of both rural and urban areas which including Kigali, as Rwanda's capital city (Fig. 1). Nyabugogo catchment cuts across 8 districts, Rulindo and Gicumbi Districts in Northern Province, Gasabo, Kicukiro, and Nyarugenge districts of Kigali city and Gatsibo, Kayonza and Rwamagana Districts of Eastern Province. The study area contains an approximate population of about 1.135.428 inhabitants.

It covers a total surface area of about $1,647 \mathrm{~km}^{2}$ with the main activity of its inhabitants being agriculture. $897 \mathrm{~km}^{2}$, which is about 54 percent of the total land space of the study area are used for agricultural activities.

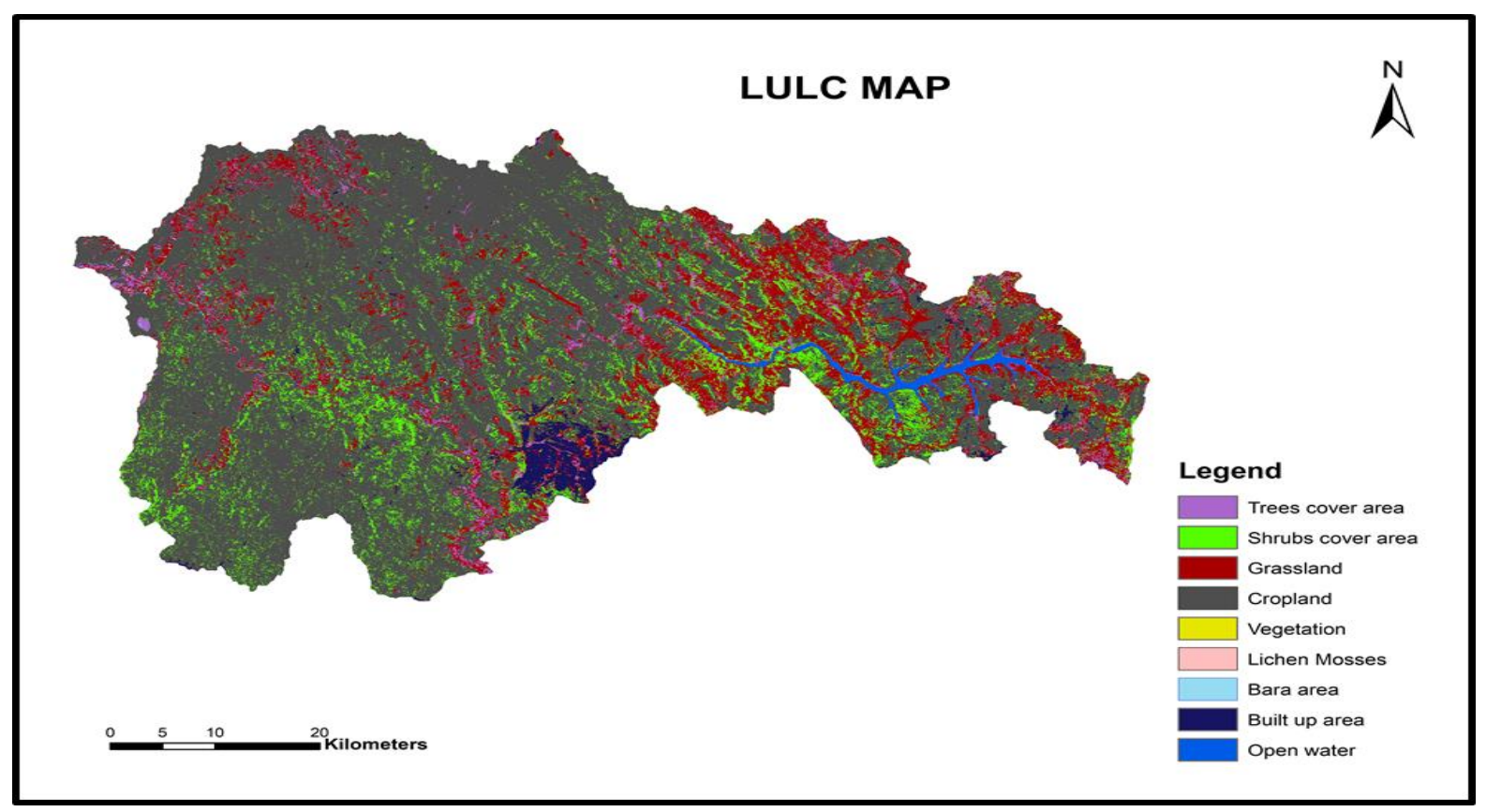

Fig. 1. Land use and land cover (LULC) map of Nyabugogo catchment.

The catchment has an equatorial and a moderate climate which has a temperature varying between 16 Celsius degree and 23 Celsius degree, depend on the altitude of the region. In Rwanda, the annual precipitation ranging from 800 millimeters to 1,600 millimeters. Rwanda has four normal 
seasons. The first season, which is a long dry season starts from June to September, the second season spans from October to December, this is a short rainy season that received $30 \%$ to $40 \%$ of the yearly rainfall with the highest rains falling in November. The third season is a short dry season which spans from December and ends in January. The fourth season which starts from February up to the end of May is the rainy season. It receives around 60\% of annual rainfall [25].

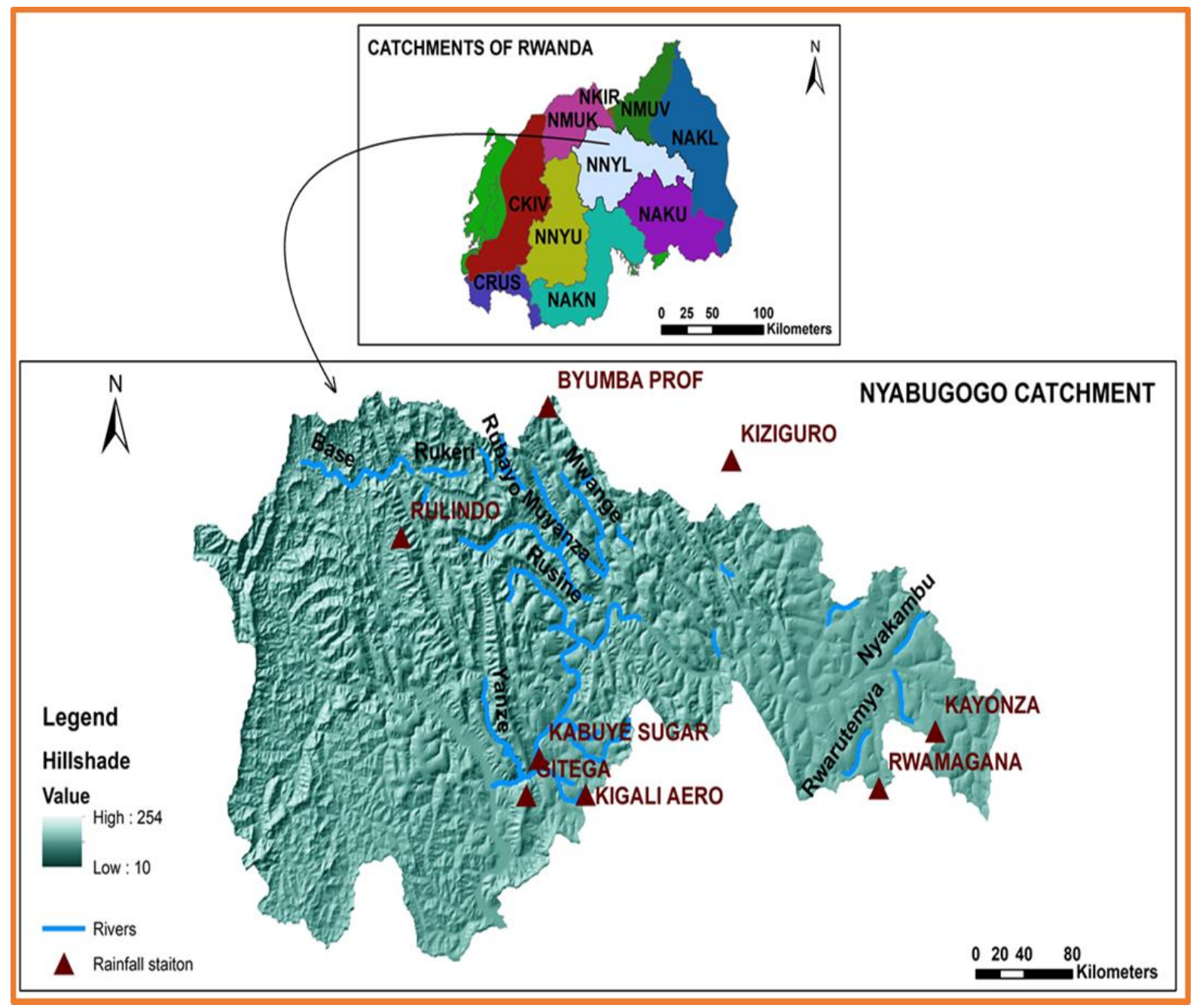

Fig.2. Location of case study area: Nyabugogo catchment.

The study area has experienced environmental degradations such as erosion of soil due largely to factors such as deforestation, lack of proper agricultural technological practices and 
illegal mining activities. These activities lead to a large deposit of heavy sediments in the River of Nyabugogo and its tributaries. This reduces the volume of water intake of the river and hydraulic structures thus causing spillover which leads to flooding. The River Nyabugogo which is fed by its tributaries, such as Marenge, Mwange and Rusine Rivers on its upstream area crosses Kigali City as the main source of flooding in Kigali City. It is also supplied by other Rivers from the urbanized area of Kigali City such as the Mpazi, Ruganwa, Rwanzekuma and Yanze Rivers.

\subsection{Data Collection}

The data used in this research have been obtained from METEO-RWANDA which has the responsibility of gauging, analyzing and keeping meteorological data and forecasting the meteorological conditions in Rwanda. The data consisted of daily annual maximum series (AMS) of rainfall depth for 37 years for all eight meteorological stations (1981-2017) found in Nyabugogo catchment for durations of time: 10min, 20min, 30min, 60min, 120min, 180min, 360min, 720min and 1440min.

Meteorological conditions in Nyabugogo catchment has relatively never stopped activity over 37 years for all Districts so that sufficient data were available to calculate a frequency analysis of extreme rainfall. There were some Daily AMS that has been digitized for the period 1993-1994 because of the genocide that happened in Rwanda against the Tutsi ethnic group in that period; these have been included in this work. The gaps were filled based on previously recorded data that were recorded in the meteorological books. These books were filled by the meteorological agents at the station regularly but only ceased in the period of instability. Data together with daily weather changes such as the rainfall depth obtained from a rain gauge every day, the beginning and ending time of rainfall are regularly recorded. 8 stations which include, Gitega, Kabuye sugar, Kigali 
Aero., Rulindo, Byumba Pref., Rwamagana, Kiziguro, and Kayonza with one metrological station representing each District.

\subsection{Method of Deriving Intensity Duration Frequency Curves}

For a deeper analysis of IDF curves, different methods can be used. There were three basic distinct approaches used while constructing IDF curves. The first involves the direct formation of Intensity-Duration-Frequency curves from annual maximum rainfall through the use of plotting the location of the equation for the return period indicated as $\mathrm{T}$ below the length of the available record. This approach generates non-smooth curves, but in the few samples when a long endless data are available [26]. In this case, where prolonged records are accessible only for daily rainfall, the empirical IDF value for $\mathrm{d}=1$ day may be applied to adjust the IDF curves and equations generated by different methodologies or to constrain the dependence of id, T on T (Koutsoyiannis, 2004).

The second approach, typically followed in practice consists of using a parametric model for id, with $\mathrm{T}$ dependence on $\mathrm{d}$ and it is constructed on the characteristical shape of empirical IntensityDuration-Frequency curves and dependency on $\mathrm{T}$ commonly depend on the fact that precipitation maxima are involved to extreme-type distributions. An astute analysis of yearly extremes aids to find parameters of the model using several criteria [26].

The third approach is so complicated. It involves fitting temporal precipitation to continuous precipitation records and then apply the model to create rainfall time-series through Monte Carlo simulations.

It is important to note that based on the model of Intensity-Duration-Frequency curves are simpler than the empirical ones and have estimated cogency also beyond the variety of the record. The 
shape of IDF curves should not be associated with a specific assumption but all available data should be used in case needed. In research, the second approach is preferred to establish an IDF relationship. The reason for the choice is that this method is simple and provides reliable results. Also, the time integration method will be used as a good way to know the parameter of statistics. 


\subsubsection{Procedures for fitting Gumbel distribution to sample data}

Rank AMS values from highest to lowest; assign a rank $m$ to each value with the highest value having a rank of 1 (one) and the lowest value a rank of $\mathbf{N}$. They constitute the observed data.

To compute the exceedance probability (p). The Gringorten and Weibull equation could be applied for approximating the cumulative probability distribution. The most problem of the Weibull formula is that it is asymptotically exact (as the number of observations approaches infinity) only for a population with an underlying uniform distribution, which is relatively rare in nature. To address this shortcoming, Gringorten proposed that the exceedance probability of observed. Data be estimated using the relation:

$\mathrm{p}=\frac{\mathrm{m}-0.44}{\mathrm{~N}+0.12}$

Where m: Rank of AMS values from highest to lowest.

It is the most recommended formula for calculating the cumulative probability distribution from measured data, for the Extreme Value Type I distribution. Calculate the reduced variable $\mathbf{u}$ from p by the equation.

$$
\mathrm{u}=-\ln [-\ln (1-\mathrm{p})]
$$

Calculate the sample mean $\mu$ s and standard deviation $\boldsymbol{\sigma s}$ by using an Excel program and find the position parameter $\mathbf{x} 0$ and the scale parameter $\mathbf{S}$ of the Gumbel distribution with the following formulae:

$X_{0}=\mu_{S}-\frac{\mu N}{\sigma N} \sigma_{S}$

$S=\frac{\sigma S}{\sigma N}$ 
Where: $\mu \mathrm{N}$ : the mean of reduced variable, $\sigma \mathrm{N}$ : the standard deviation of the reduced variable.

$\mu \mathbf{N}$ and $\boldsymbol{\sigma N}$ are shown in the table of Parameters of reduced Gumbel Distribution. They both depend on the number of sample points. They use the formulae below which are the Gumbel mean $\left(\boldsymbol{\mu}_{\mathbf{G}}\right)$ and Standard deviation ( $\left.\boldsymbol{\sigma}_{\mathbf{G}}\right)$ and finally for each rank, the Gumbel variable is obtained by the use of the formula. They constitute the expected data.

$$
\begin{aligned}
& \mu_{G}=X_{0}+0.5772 * S \\
& \sigma_{G}=1.2825 * S \\
& X_{G}=\left(X_{0}+(u * S)\right)
\end{aligned}
$$

\subsubsection{Preparation of short-duration rainfall data}

To estimate the short duration rainfall from daily rainfall data, many researches like [29-32] used an empirical reduction formula to estimate different hourly durations from daily precipitation values. Based on [33], the empirical reduction formula in Eq. 3.8 gives the best estimation of shortduration rainfall. In this research, Eq.3.8 was applied to estimate short duration rainfall in Nyabugogo catchment (e.g.10 min, $20 \mathrm{~min}, 30 \mathrm{~min}, 1$, 2, 3, 4, 6 and 8 h):

$\mathrm{P}_{\mathrm{t}}=\mathrm{P}_{24}(\mathrm{t} / 24)^{1 / 3}$

Where: $\mathbf{P}_{\mathbf{t}}=$ Precipitation in $\mathrm{mm}$ for a given duration $\mathbf{t}$ hours, $\mathbf{P}_{\mathbf{2 4}}=$ Daily Precipitation data in $\mathrm{mm}$, and $\mathbf{t}=$ Shorter duration in hours. This equation has been chosen because it gives the best estimation of short-duration rainfall. 


\subsubsection{Goodness of Fit tests}

These tests can be applied reliably in climate statistics to assist to find the best distribution to use to fit the given data. Goodness of fit tests determine test-statistics, which are applied to investigate how well the data fits the given distribution. They describe also how the observed data values and the expected values are different when the distribution is being tested.

\subsubsection{The chi-square test $\mathrm{x}^{2}(\mathrm{v})$}

The Chi-Squared test is applied to find out if a sample comes from a provided distribution. ChiSquared test should be well-known that the statistical test is not considered to have a high power. By putting the observed data and the expected values into intervals to determine the frequencies of both variables in each class. This can be well expressed by a histogram of frequencies (Fig. 2b) and rearrange the classification so that the minimum expected frequency in each class becomes 5 or great. The classes with low frequency should be merged to this end. Then after compute the chisquare value for all intervals.

$\mathrm{X}^{2}(\mathrm{~V})=\sum_{\mathrm{i}}^{\mathrm{n}} \frac{(\mathrm{Oi}-\mathrm{Ei})}{\mathrm{Ei}}$

Where $\mathrm{V}$ is the degree of freedom and equals $\mathrm{n}-\mathrm{k}-1$, here $\mathrm{n}$ symbolize the number of intervals and $\mathrm{k}$ is the distribution number of parameters obtained from the sample statistics; the constraints imposed on the fitting process. Compare the value so obtained to the tabulated Chi-square value $\mathrm{X}^{2}{ }_{0.95}$ (Chi-Square Distribution Table); the null hypothesis will be accepted if $\mathbf{X}^{\mathbf{2}}<\mathbf{X}^{\mathbf{2}} \mathbf{0 . 9 5} \quad$ (Eq.3.10) and rejected otherwise. 


\subsubsection{Kolmogorov-Smirnov Test}

The Kolmogorov-Smirnov test statistic is built on the greatest vertical distance from the empirical and theoretical cumulative distribution function. A hypothesis is rejected if the critical value at a chosen significance level is lesser than the test statistic (D), otherwise accepted. The samples are supposed to be from a cumulative distribution function.

$D=\max |F 0(x)-F t(x)|$

Where D: maximum deviation, F0 (x) be the sample cumulative distribution function based on $\mathrm{N}$ observations. For any observed $\mathrm{x}, \mathrm{F} 0(\mathrm{x})=\frac{\mathrm{j}}{\mathrm{N}}$, where $\mathrm{j}$ is the number of observations less than or equal to $\mathrm{x}$ and $\operatorname{Ft}(\mathrm{x})$ be the specified theoretical cumulative distribution function under the hypothesis.

\subsubsection{The procedure for designing of IDF curves}

Tabulation of yearly rainfall data, regular daily rain data from the long term is used to get current trends in the rainfall intensity followed by the formulation of short-duration rainfall data. Applying the Indian Meteorological Department expression, a short duration rainfall series is obtained from Daily Precipitation data (Table 1) and then determine Probability Distribution. In this research, Gumbel's Extreme. The value distribution method is applied for probability distribution for each picked out duration data series. [34] showed that hydrological studies can be expressed by the expression below depicting hydrologic Frequency analysis: The precipitation (PT) comparable to an estimated return period (T) applying the GEVDM is given by:

$$
\mathrm{PT}=\sigma+\mathrm{K} . \mathrm{S}
$$


Where: $\sigma$ : Average annual daily maximum rainfall (AADMR), S: Standard deviation of (AADMR) and K: Frequency Factor given by:

$K=-\frac{\sqrt{6}}{\pi}\left[0.5772+\ln \left[\ln \left[\frac{T}{T-1}\right]\right]\right.$

Using the above equation, Frequency Factors for the return periods of 2, 5,10,25,50 and 100 years are calculated and the values are of Frequency factor should be obtained respectively.

Those parameters of frequency factor are applied to get precipitation (PT) matching to return periods of 2 years to 100 years for durations of $10 \mathrm{~min}$ to $1440 \mathrm{~min}$.

At this point, the rainfall intensity $\left(\mathrm{I}_{\mathrm{T}}\right)$ is obtained for the return period $\mathrm{T}$ from the following equation:

$\mathrm{I}_{\mathrm{T}}=\frac{\mathrm{P}_{\mathrm{t}}}{\mathrm{T}_{\mathrm{d}}}$

Where $T_{d}$ is the duration in hours. The frequency of the precipitation is well-defined by reference to the AMS, which contains the highest values observed in every year. The using the Least Square method, Orange software, or Excel sheet to find parameters $\mathrm{x}$ and $\mathrm{y}$ for different return periods. Equation (Eq.3.15) in the formation of the IDF empirical formula which is applied in this research [35].

$$
\mathrm{I}=\mathrm{X} *(\mathrm{td})^{-\mathrm{y}}
$$

Where td: is the rainfall duration in a minute, I: is the rainfall intensity in millimeter per hour. $\mathbf{X}$ and $\mathbf{y}$ are fitting parameters. These empirical formulas are commonly applied in different hydrological uses. This formula indicates that for a given return period, the rainfall duration increases with a decrease in rainfall intensity. Finally finding the correlation coefficient by using the Excel sheet. The correlation coefficient (R) was established to obtain the best-fit IDF empirical 
equation. For any particular return period, the formula that allows the correlation coefficient value nearer to one has the best fit. So after all these steps, we found peak flow (hydrological discharge (Q)ogy) which was compared with a hydraulic discharge (Qlics) [20].

$$
\begin{aligned}
& \mathrm{Q}_{\operatorname{logy}}=(\mathrm{ARF}) \mathrm{C}_{\mathrm{f}} \mathrm{CIA} \\
& \mathrm{Q}_{\operatorname{logy}}=(\mathrm{ARF}) * \mathrm{C}_{\mathrm{f}} * \mathrm{C} *\left(\mathrm{X} *(\mathrm{td})^{-\mathrm{y}}\right) * \mathrm{~A} \\
& A R F=[1.343-0.09 \ln (A)] T_{d} \\
& \mathrm{C}=\frac{Q}{\mathrm{P}} \\
& \mathrm{Q}_{\text {lics }}=\frac{1}{\mathrm{n}} * \mathrm{R}^{2 / 3} * \sqrt{\mathrm{S}} * \mathrm{Ac}
\end{aligned}
$$

Where: $\mathbf{Q}_{\mathbf{l o g y}}=$ predicted peak rate of runoff $\left(\mathrm{m}^{3} / \mathrm{sec}\right), \mathbf{Q}_{\text {lics }}=$ Hydraulic discharge $\left(\mathrm{m}^{3} / \mathrm{sec}\right)$, $\mathbf{C}=$ runoff coefficient, $\mathbf{Q}=$ Runoff volume $\left(\mathrm{m}^{3}\right)$ and $\mathbf{P}=$ Rainfall volume $\left(\mathrm{m}^{3}\right) \mathbf{I}=\mathbf{X} *(\mathbf{t d})^{-\mathbf{y}}=$ Rainfall intensity $(\mathrm{mm} / \mathrm{hr}),.(\mathbf{A R F})=$ Area Reduction Factor, $\mathbf{A}=$ drainage area (in ha), $\mathbf{C} \mathbf{f}=$ Frequency Factors for Rational Formula, $\mathbf{A} \mathbf{c}=$ Cross section Area of hydraulic structure $\left(\mathrm{m}^{2}\right), \mathbf{n}=$ Manning roughness coefficient, $\mathbf{S}=$ Channel bottom slope, in meters per meter and $\mathbf{R}=$ Hydraulic Radius in $(\mathrm{m})$, in meters, $\mathrm{x}$ and $\mathrm{y}$ are the parameters to fit the IDF curve.

Least Square method is applied to get parameters $\mathbf{x}$ and $\mathbf{y}$ for various return periods and the outcomes are shown in the table of rainfall Intensity-Duration-Frequency empirical equation for corresponding return period and their correlation coefficients for all meteorological stations.

\section{RESULT AND DISCUSSION}

To reduce the risk of failure of hydraulic structures and to design a reliable and durable construction, hydraulic structures should be designed and constructed with resilience to withstand 
future climate change. To build such a future climate-resistant infrastructure, the design storms estimated from the IDF curves should be reviewed to adapt the infrastructure to a changing climate through fulfilling adaptation actions [10]. As the non-performance of different categories of hydraulic structures occurs at different rainfall thresholds [36], the predicted changes in common return periods for hydraulic structure design (means: a storm with heavy rain of 2,5,10,50 and 100 years of return periods) are studied.

\subsection{Application of Procedures for Gitega Meteorological station}

\section{Daily Annual Maxima Series (AMS) analysis}

As from the table of parameters of reduced Gumbel Distribution, here $\mu \mathrm{N}$ and $\sigma \mathrm{N}$ are found to be equal to 0.54180 and 1.13390 respectively for $\mathrm{N}=37$. Here sampled extreme rainfall depth, in millimeter are arranged in descendent order, the exceedance probabilities got with Gringorten formula, the reduced valuable $\mathrm{u}$ is calculated using the expression Eq.3.2 and the expected values as were generated by Gumbel distribution were computed in the (Table S1) (Borga et al., 2005).

The frequencies of the observed values and expected values for the given ranges are calculated.

This enables us to plot into a diagram frequency as expressed in terms of ranges; furthermore, to make tests of best fit, the histograms in (Fig. 2b) give an idea of the distribution of data and (Fig. 2a) showed the Annual Maximum Daily Rainfall. 

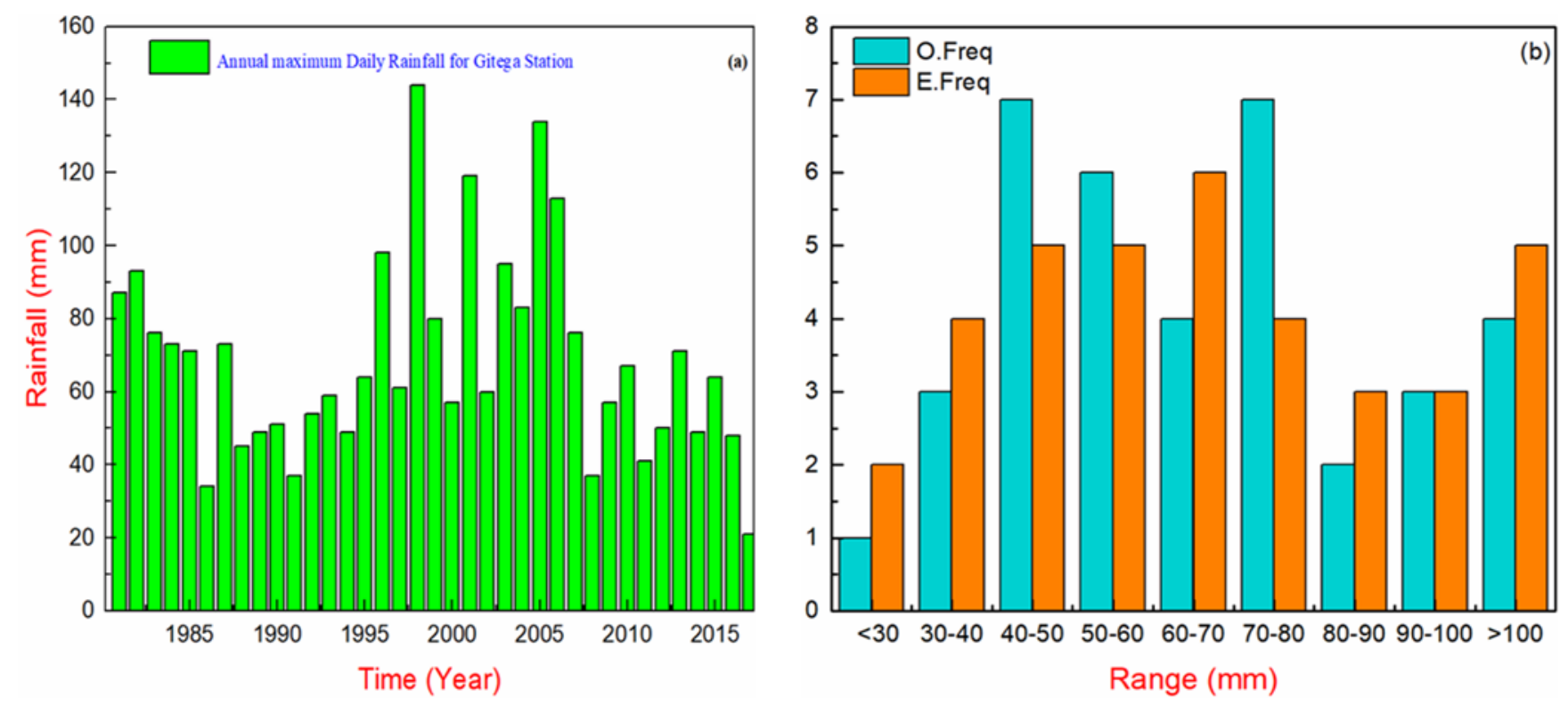

Fig. 3. (a) Annual Maximum Daily Rainfall for Gitega station and (b) Distribution of observed and expected frequencies.

$\mathrm{O}$ freq: Observed frequency and $\mathrm{E}$ freq: expected frequency

In Figure 3a, the results showed that the annual maximum daily rainfall (AMDR) of $144 \mathrm{~mm}$ has been observed in Gitega station, Nyarugenge District but for the whole catchment AMDR of 270 mm was observed also at Rwamagana station, Rwamagana District for the last 37 years. This is because maybe in Rwamagana District, we are found grassland, open water, and some trees as we have seen in Figure 1; these made transpiration from vegetation and soil and also evaporation from open water which leads much condensation into atmosphere [38, 39].

The frequencies of the observed values and expected values for the given ranges are calculated before leading to the chi-square test. Intervals of low frequencies have been put together so that the minimum frequency becomes greater than or equal to five. The computed chi-square showed that $\mathrm{X}^{2}=4.6$. For $\mathrm{n}=5$ number of interval and $\mathrm{k}=2$ number of constraints, the degree of freedom is equal to $v=5-2-1=2$. The $5 \%$ non-acceptance limit would be the ninety-fifth percentile of 
the Chi-Square distribution (CSD) having 2 degrees of freedom, which is equal to 0.103 from the Chi-Square Distribution Table S8. The level of significance, $\alpha=0.05$ gives rise to a critical value of 0.103 which is applied in this research. Also, if the test statistic is lesser than the critical value $(0.103<4.6)$, the hypothesis is accepted. [40], used this method and after making his calculations, he found that the test statistic was greater than the critical value because the significant level, produced a critical value of 12.592 which is applied in his report.

The Kolmogorov test showed that the highest difference is equal to 0.0692 and the critical value for Kolmogorov-Smirnov given in the Critical values of Kolmogorov-Smirnov test table Table S9 for eight intervals and a $5 \%$ significant level, is 0.457 . Since $0.0692<0.457$ the Hypothesis is accepted at 0.05 significant level. The number of intervals were considered here instead of the sample size (37) for the Gitega station. Processes used for this Gitega station (Kolmogorov test) are similar for all remaining seven stations such as Kanombe Aero, Kabuye sugar, Rulindo, Byumba Pref, Rwamagana, Kiziguro, and Kayonza station, and the Hypothesis is accepted at 0.05 significant level. This process has been used [41], the same Hypothesis was accepted at a 0.05 significant level.

Here, the results for the goodness of fit tests are examined for the statistical distributions in question. Goodness of fit tests, for all storm durations the Gumbel's Extreme-Value Distribution method appears to have the most appropriate fit. 


\subsection{Preparation of short-duration rainfall data}

The relationship of short-duration rainfall (SDR) with the daily rainfall value was calculated and represented to improve the model of regression. Related to the nature of curvature and to obtain reliable estimations, the proposed two equations were mentioned: the rainfall duration less or equal to 2 hours, and the second one starts from above $2 \mathrm{~h}$ up to 24 hours; means less than 1 day. Here, there are some opportunities of having little different estimation of rainfall values for changing the duration which is 2 hours, in this special research.

\begin{tabular}{llllllllllll}
\hline No & Years & AMDR & $\mathbf{1 0} \mathbf{m i n}$ & $\mathbf{2 0} \mathbf{m i n}$ & $\mathbf{3 0} \mathbf{m i n}$ & $\mathbf{1 h r}$ & $\mathbf{2 h r}$ & $\mathbf{3 h r}$ & $\mathbf{6 h r}$ & $\mathbf{1 2 h r}$ & $\mathbf{2 4 h \mathbf { h }}$ \\
\hline $\mathbf{1}$ & $\mathbf{1 9 8 1}$ & $\mathbf{8 7}$ & 16.6498 & 21.1426 & 24.2499 & 30.4824 & 38.3168 & 43.8026 & 55.0604 & 69.2117 & 87 \\
$\mathbf{2}$ & $\mathbf{1 9 8 2}$ & $\mathbf{9 3}$ & 17.7981 & 22.6007 & 25.9223 & 32.5847 & 40.9594 & 46.8234 & 58.8577 & 73.9849 & 93 \\
$\mathbf{3}$ & $\mathbf{1 9 8 3}$ & $\mathbf{7 6}$ & 14.5447 & 18.4694 & 21.1838 & 26.6283 & 33.4722 & 38.2643 & 48.0988 & 60.4608 & 76 \\
$\mathbf{4}$ & $\mathbf{1 9 8 4}$ & $\mathbf{7 3}$ & 13.9705 & 17.7404 & 20.3476 & 25.5772 & 32.1509 & 36.7539 & 46.2001 & 58.0742 & 73 \\
$\mathbf{5}$ & $\mathbf{1 9 8 5}$ & $\mathbf{7 1}$ & 13.5878 & 17.2543 & 19.7901 & 24.8765 & 31.27 & 35.7469 & 44.9344 & 56.4831 & 71 \\
$\mathbf{6}$ & $\mathbf{1 9 8 6}$ & $\mathbf{3 4}$ & 6.50682 & 8.26264 & 9.47697 & 11.9127 & 14.9744 & 17.1182 & 21.5179 & 27.0482 & 34 \\
$\mathbf{7}$ & $\mathbf{1 9 8 7}$ & $\mathbf{7 3}$ & 13.9705 & 17.7404 & 20.3476 & 25.5772 & 32.1509 & 36.7539 & 46.2001 & 58.0742 & 73 \\
$\mathbf{8}$ & $\mathbf{1 9 8 8}$ & $\mathbf{4 5}$ & 8.61197 & 10.9358 & 12.543 & 15.7668 & 19.819 & 22.6565 & 28.4795 & 35.7991 & 45 \\
$\mathbf{9}$ & $\mathbf{1 9 8 9}$ & $\mathbf{4 9}$ & 9.37748 & 11.9079 & 13.658 & 17.1683 & 21.5807 & 24.6704 & 31.011 & 38.9813 & 49 \\
$\mathbf{1 0}$ & $\mathbf{1 9 9 0}$ & $\mathbf{5 1}$ & 9.76023 & 12.394 & 14.2154 & 17.869 & 22.4616 & 25.6774 & 32.2768 & 40.5724 & 51 \\
$\mathbf{1 1}$ & $\mathbf{1 9 9 1}$ & $\mathbf{3 7}$ & 7.08095 & 8.9917 & 10.3132 & 12.9638 & 16.2957 & 18.6287 & 23.4165 & 29.4348 & 37 \\
$\mathbf{1 2}$ & $\mathbf{1 9 9 2}$ & $\mathbf{5 4}$ & 10.3344 & 13.123 & 15.0517 & 18.9201 & 23.7829 & 27.1878 & 34.1754 & 42.959 & 54 \\
$\mathbf{1 3}$ & $\mathbf{1 9 9 3}$ & $\mathbf{5 9}$ & 11.2912 & 14.3381 & 16.4453 & 20.672 & 25.985 & 29.7052 & 37.3398 & 46.9367 & 59 \\
$\mathbf{1 4}$ & $\mathbf{1 9 9 4}$ & $\mathbf{4 9}$ & 9.37748 & 11.9079 & 13.658 & 17.1683 & 21.5807 & 24.6704 & 31.011 & 38.9813 & 49
\end{tabular}




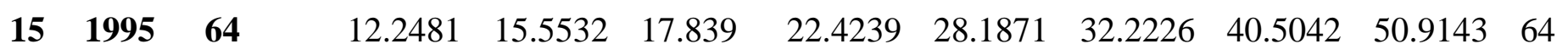

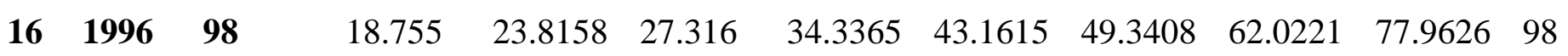
$\begin{array}{llllllllllll}17 & 1997 & 61 & 11.674 & 14.8241 & 17.0028 & 21.3727 & 26.8658 & 30.7121 & 38.6056 & 48.5277 & 61\end{array}$

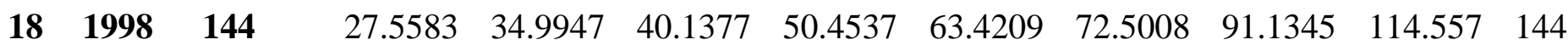

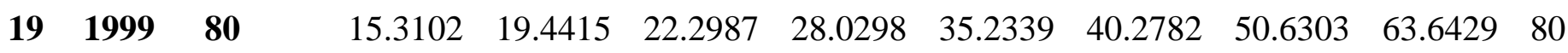
$\begin{array}{llllllllllll}20 & \mathbf{2 0 0 0} & \mathbf{5 7} & 10.9085 & 13.8521 & 15.8879 & 19.9712 & 25.1041 & 28.6982 & 36.0741 & 45.3456 & 57\end{array}$

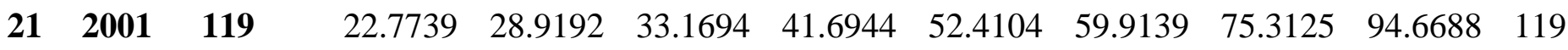

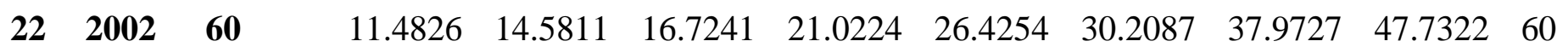

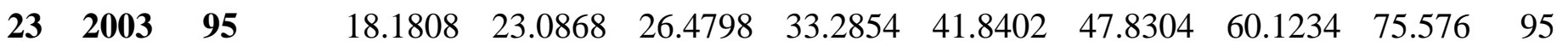

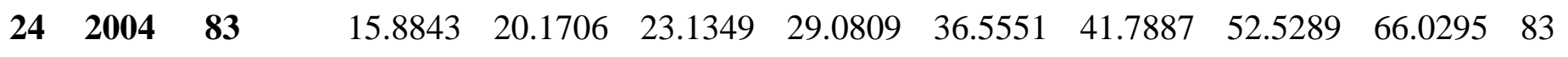

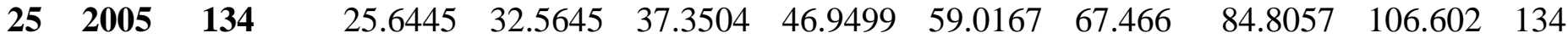

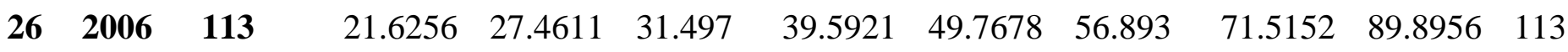

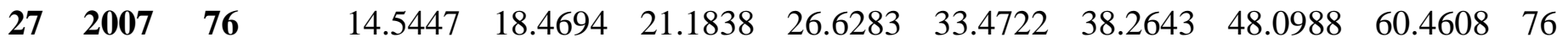
$\begin{array}{llllllllllll}28 & 2008 & 37 & 7.08095 & 8.9917 & 10.3132 & 12.9638 & 16.2957 & 18.6287 & 23.4165 & 29.4348 & 37\end{array}$ $\begin{array}{llllllllllll}29 & 2009 & 57 & 10.9085 & 13.8521 & 15.8879 & 19.9712 & 25.1041 & 28.6982 & 36.0741 & 45.3456 & 57\end{array}$ $\begin{array}{llllllllllll}30 & 2010 & 67 & 12.8223 & 16.2823 & 18.6752 & 23.475 & 29.5084 & 33.733 & 42.4028 & 53.3009 & 67\end{array}$ $\begin{array}{llllllllllll}31 & 2011 & 41 & 7.84646 & 9.96377 & 11.4281 & 14.3653 & 18.0574 & 20.6426 & 25.948 & 32.617 & 41\end{array}$ $\begin{array}{llllllllllll}32 & 2012 & \mathbf{5 0} & 9.56885 & 12.1509 & 13.9367 & 17.5186 & 22.0212 & 25.1739 & 31.6439 & 39.7768 & 50\end{array}$

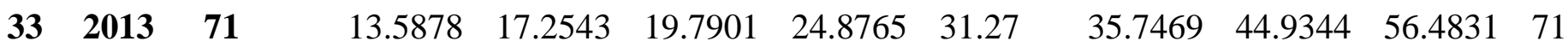
$\begin{array}{llllllllllll}34 & 2014 & 49 & 9.37748 & 11.9079 & 13.658 & 17.1683 & 21.5807 & 24.6704 & 31.011 & 38.9813 & 49\end{array}$

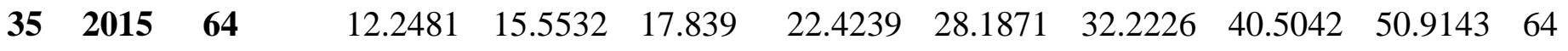

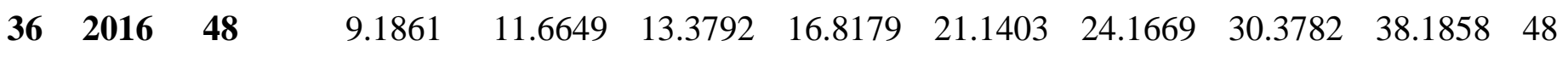

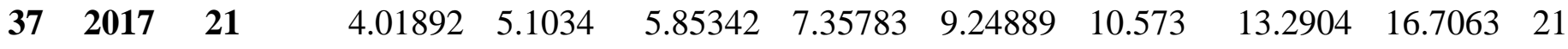


Mean ( $\sigma)$

13.1378

$16.6829 \quad 19.1347 \quad 24.0526$

$30.2345 \quad 34.5631$

43.4462 54.6125

68.6486

St.Dev. S

5.2632

6.683447 .66568

9.63586

$\begin{array}{llll}12.1124 & 13.8465 & 17.4053 & 21.8786\end{array}$

Table 1. Shorter Duration Rainfalls Derived from Max. Daily Rainfall using Indian Meteorological Department $1 / 3^{\text {rd }}$ rule.

The precipitation of any duration near to 2 hours should be determined by applying both equations and the higher value should be established for determining rainfall value. SDR data of the close to automatic meteorological station were checked out for testing the output design graphs [42].

Processes used for this Gitega station (Table 1) are similar for all remaining seven stations such as Kanombe Aero, Kabuye sugar, Rulindo, Byumba Pref, Rwamagana, Kiziguro, and Kayonza station.

Estimated rainfall in $\mathrm{mm}$ and its intensities in $\mathrm{mm} / \mathrm{hr}$ for all return periods and its corresponding durations were analyzed using the Gumbel technique. The application of the Gumbel frequency factor method is highly useful for estimating frequencies of rainfall and storm floods [43]. From the raw data, the extreme rainfall $\left(\mathrm{P}_{\mathrm{T}}\right)$, the average and standard deviation for the duration $(10,20,30,60,120,180,360,720$ and 1440 minutes) were estimated from the annual maximum 24hrs rainfall IMERF (Indian Meteorological empirical Reduction Formula). In terms of frequency, as shown by the curves of growing factor variation KT, it's possible to note how the effect of climate change can be visualized in the eight established Districts through the increase in the frequency of extreme events KT is kept as constant, the equivalent return period value is reduced taking into account the flood projections [22]. The various projected duration data were applied in Gumbel's Extreme Probability Method to calculate precipitation (PT) values and intensities ( $\mathrm{I}_{\mathrm{T}}$ ) for the Districts of Nyabugogo Catchment. (Table 2) shows rainfall frequency 
values, intensities $\left(\mathrm{I}_{\mathrm{T}}\right)$ for diverse durations and return periods using the Gumbel distribution

Method for Gitega station (represents Nyarugenge District) were computed.

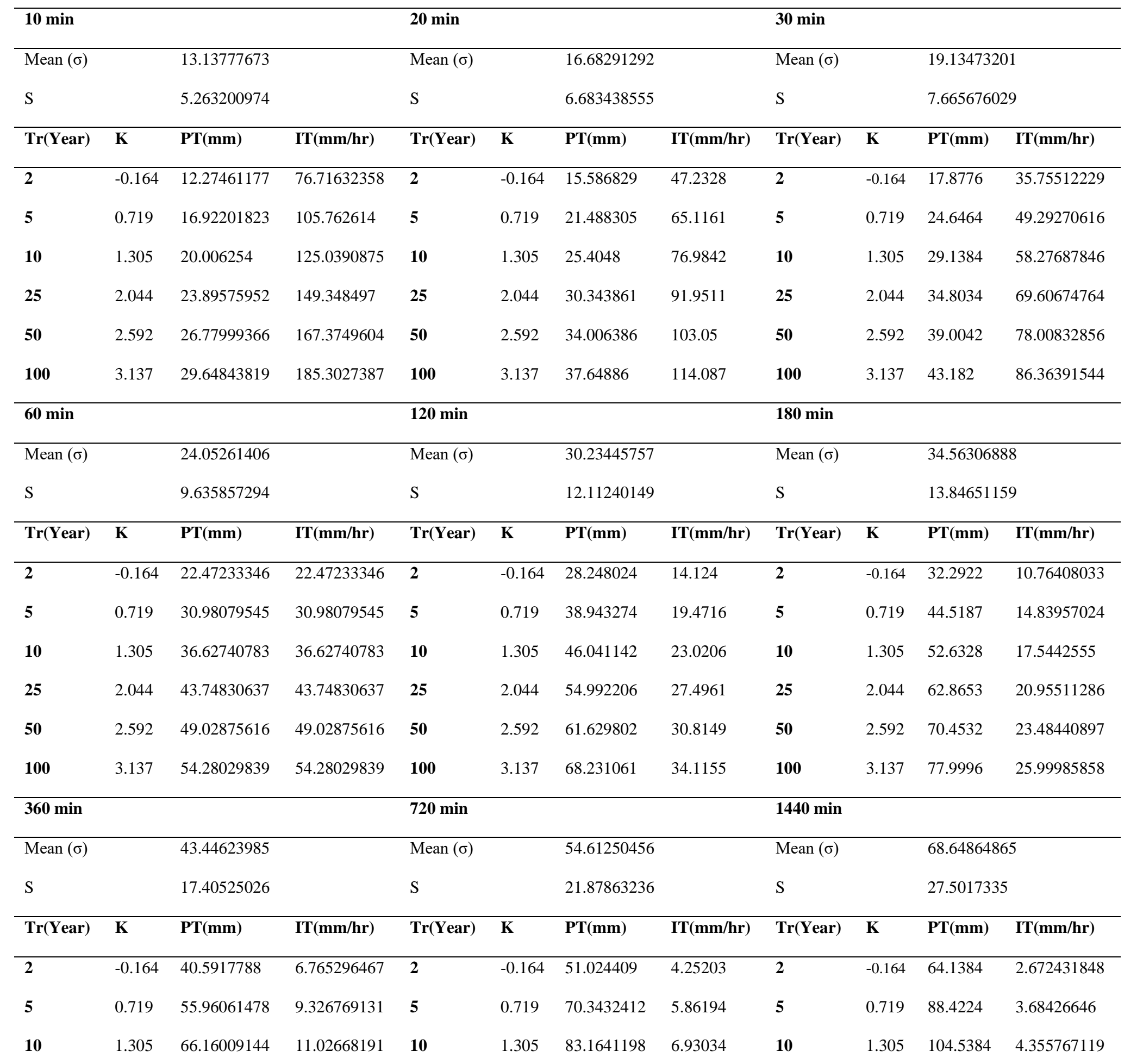




\begin{tabular}{lllllllllllll}
$\mathbf{2 5}$ & 2.044 & 79.02257138 & 13.17042856 & $\mathbf{2 5}$ & 2.044 & 99.3324291 & 8.2777 & $\mathbf{2 5}$ & 2.044 & 124.8622 & 5.20259133 & \\
$\mathbf{5 0}$ & 2.592 & 63.44349011 & 10.57391502 & $\mathbf{5 0}$ & 2.592 & 111.32192 & 9.27683 & $\mathbf{5 0}$ & 2.592 & 139.9331 & 5.830547578 \\
$\mathbf{1 0 0}$ & 3.137 & 98.04650991 & 16.34108499 & $\mathbf{1 0 0}$ & 3.137 & 123.245774 & 10.2705 & $\mathbf{1 0 0}$ & 3.137 & 154.9216 & 6.45506611 \\
\hline
\end{tabular}

Table 2.Computed frequency rainfall (PT) values and intensities (IT) for different durations and return periods using Gumbel Method for Gitega station (Nyarugenge District).

Results in table 2 show clearly that for those short duration, the rainfall intensity increases and also increase with increasing precipitation in the return period of 2,5,10 50 and 100 years. Similarly, for all other seven stations rainfall frequency $\left(\mathrm{P}_{\mathrm{T}}\right)$ values and intensities $\left(\mathrm{I}_{\mathrm{T}}\right)$ for different durations. The same results are found by [44] when they computed IDF Curves before and after 1980 in Toronto (Canada) and their results were that the intensity decreases particularly with an increase of return period of 5,10,20 and 50 years.

From the calculated rainfall $\left(\mathrm{P}_{\mathrm{T}}\right)$ values and intensities ( $\left.\mathrm{I}_{\mathrm{T}}\right)$ in (Fig.4 and 5), Rainfall IDF curves were developed for the eight Districts of Nyabugogo Catchment. As the curves show the rainfall intensity increases when rainfall duration reduces. Similar results were also obtained by (Nhat et al., 2006; Rasel \& Hossain, 2015) in which an equation was designed where rainfall Intensity was developed in 10-minute increments for different return periods by using GEVDM. 

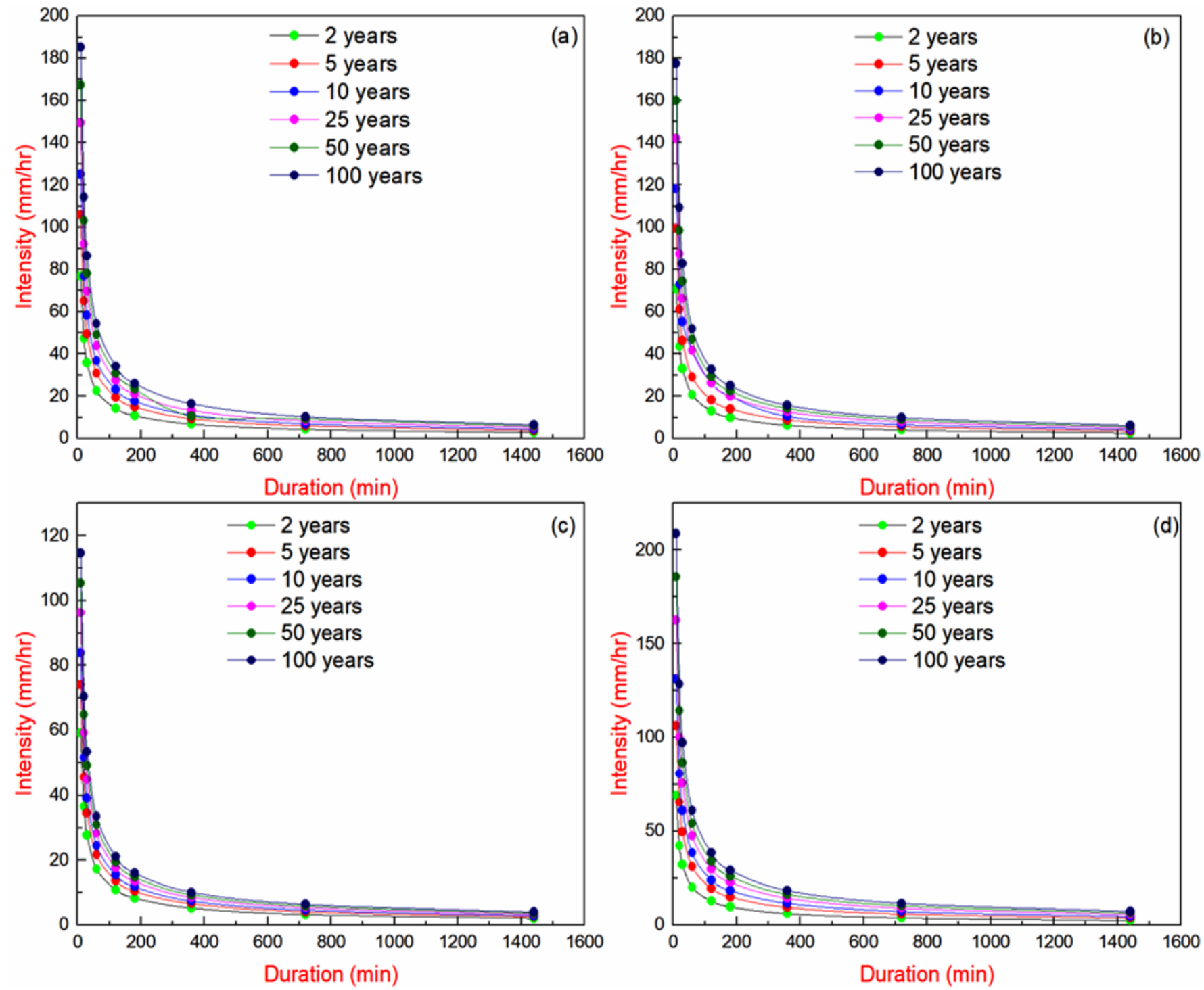

Fig. 4. Rainfall IDF curve for (a) Gitega station-Nyarugenge District, (b) Kigali Aero-Kicukiro District, (c) Byumba Pref. station-Gicumbi District and (d) Rwamagana station-Rwamagana District. 

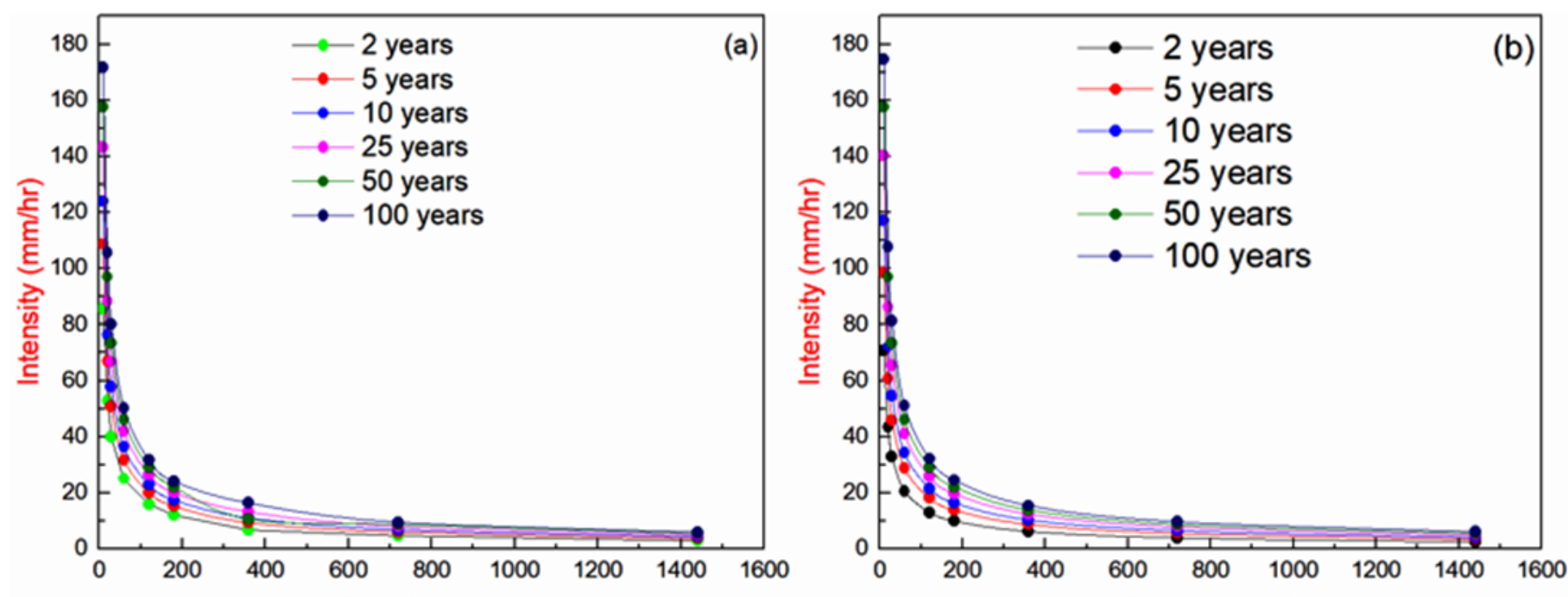

Duration (min)
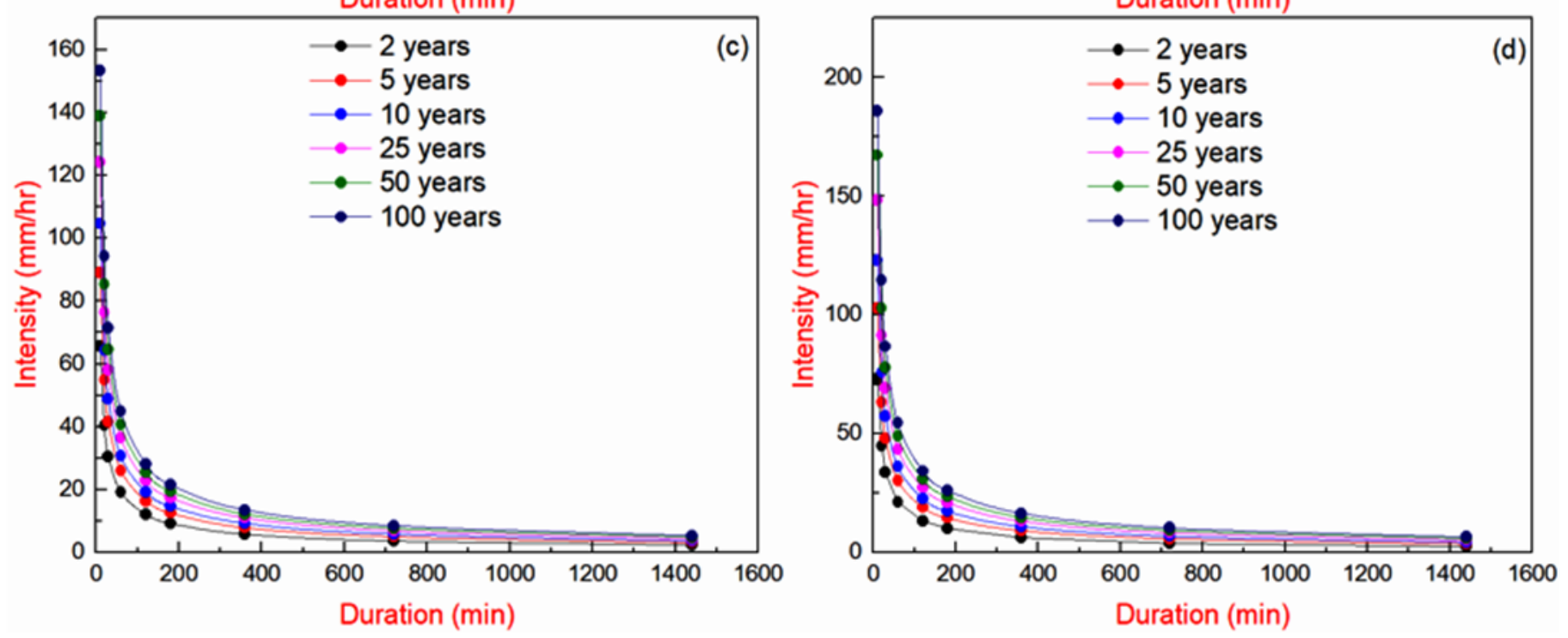

Fig.5. Rainfall IDF curve for (a) Kabuye sugar station-Gasabo District, (b) Rulindo station-Rulindo District, (c) Kiziguro station-Gatsibo District and (d) Kayonza station- Kayonza District.

In whole catchment, referring to the results from the figure 4 and figure 5, the highest intensities which are $208.77,186.02,185.3,177.43,174.69,171.74,153.24$ and $114.57 \mathrm{~mm} /$ hour will occur at Rwamagana District, Kayonza District, Nyarugenge District, Kicukiro District, Rulindo District, Gasabo District, Gatsibo District and Gicumbi District respectively; these mean that the highest rainfall will happen after 100 years. Flood measures should be taken before and any 
hydraulic structures should be designed well with referring to these results. The same results are stated by [29, 30, 42], they showed that the intensity increases with an increase of precipitation.

According to the intensity-duration- frequency curves, rainfall (PT) estimates increase with an increase in the return period as it can be seen from (Tables 3-6) and (Table S2 to Table S5) and also result showed that all rainfall intensities decrease with rainfall duration in all return's periods. Also, a rainfall in any given duration will have a higher intensity if its return period is high [10]. These tables indicate the design of Rainfall IDF empirical equation for respective return period and their correlation coefficient, R of all 8 Districts located in Nyabugogo Catchment using similar means. Those designed period equations can be used from 2017 to 2117 which means, the range of the design is 100 years as a designed period.

\section{Return}

Period( Year)

$\mathbf{x} \quad$ Equation

\section{Correlation}

\section{Coefficient (R)}

\begin{tabular}{lllll}
\hline 256.25 & 0.67 & $\mathrm{I}=356.25(\mathrm{td})^{-0.67}$ & $\mathrm{R}=1$ \\
5 & 491.13 & 0.67 & $\mathrm{I}=491.13(\mathrm{td})^{-0.67}$ & $\mathrm{R}=1$ \\
10 & 580.64 & 0.67 & $\mathrm{I}=580.64(\mathrm{td})^{-0.67}$ & $\mathrm{R}=1$ \\
25 & 693.53 & 0.67 & $\mathrm{I}=693.53(\mathrm{td})^{-0.67}$ & $\mathrm{R}=1$ \\
50 & 812.46 & 0.67 & $\mathrm{I}=812.46(\mathrm{td})^{-0.67}$ & $\mathrm{R}=1$ \\
100 & 860.49 & 0.67 & $\mathrm{I}=860.49(\mathrm{td})^{-0.67}$ & $\mathrm{R}=1$ \\
\hline
\end{tabular}

Table 2. Rainfall IDF empirical equation for respective return period and their correlation coefficient, $\mathrm{R}$ for Nyarugenge District. 


\begin{tabular}{lllll}
\hline $\begin{array}{l}\text { Return } \\
\text { Period(Year) }\end{array}$ & $\mathbf{x}$ & Equation & $\begin{array}{l}\text { Correlation } \\
\text { Coefficient }(\mathbf{R})\end{array}$ \\
\hline & & & & \\
2 & 328.62 & 0.67 & $\mathrm{I}=328.62(\mathrm{td})^{-0.67}$ & $\mathrm{R}=1$ \\
5 & 461.11 & 0.67 & $\mathrm{I}=461.11(\mathrm{td})^{-0.67}$ & $\mathrm{R}=1$ \\
10 & 585.93 & 0.67 & $\mathrm{I}=585.93(\mathrm{td})^{-0.67}$ & $\mathrm{R}=1$ \\
25 & 659.93 & 0.67 & $\mathrm{I}=659.93(\mathrm{td})^{-0.67}$ & $\mathrm{R}=1$ \\
50 & 742.15 & 0.67 & $\mathrm{I}=742.15(\mathrm{td})^{-0.67}$ & $\mathrm{R}=1$ \\
100 & 823.93 & 0.67 & $\mathrm{I}=823.93(\mathrm{td})^{-0.67}$ & $\mathrm{R}=1$ \\
\hline
\end{tabular}

Table 4. Rainfall IDF empirical equation for respective return period and their correlation coefficient, R for Kicukiri District.

\begin{tabular}{lllll}
\hline Return & $\mathbf{x}$ & $\mathbf{y}$ & Equation & Correlation
\end{tabular}

Period( Year)

\section{Coefficient (R)}

$\begin{array}{lllll}2 & 275.32 & 0.67 & \mathrm{I}=275.32(\mathrm{td})^{-0.67} & \mathrm{R}=1 \\ 5 & 343.99 & 0.67 & \mathrm{I}=343.99(\mathrm{td})^{-0.67} & \mathrm{R}=1 \\ 10 & 389.57 & 0.67 & \mathrm{I}=389.57(\mathrm{td})^{-0.67} & \mathrm{R}=1 \\ 25 & 447.04 & 0.67 & \mathrm{I}=447.04(\mathrm{td})^{-0.67} & \mathrm{R}=1 \\ 50 & 489.66 & 0.67 & \mathrm{I}=489.66(\mathrm{td})^{-0.67} & \mathrm{R}=1 \\ 100 & 532.05 & 0.67 & \mathrm{I}=532.05(\mathrm{td})^{-0.67} & \mathrm{R}=1\end{array}$

Table 5. Rainfall IDF empirical equation for respective return period and their correlation coefficient for Gicumbi District. 


\begin{tabular}{lllll}
\hline $\begin{array}{l}\text { Return } \\
\text { Period( Year) }\end{array}$ & $\mathbf{x}$ & $\mathbf{y}$ & Equation & $\begin{array}{l}\text { Correlation } \\
\text { Coefficient }(\mathbf{R})\end{array}$ \\
\hline & & & & \\
2 & 320.69 & 0.67 & $\mathrm{I}=320.69(\mathrm{td})^{-0.67}$ & $\mathrm{R}=1$ \\
5 & 494.24 & 0.67 & $\mathrm{I}=494.24(\mathrm{td})^{-0.67}$ & $\mathrm{R}=1$ \\
10 & 609.24 & 0.67 & $\mathrm{I}=609.24(\mathrm{td})^{-0.67}$ & $\mathrm{R}=1$ \\
25 & 754.67 & 0.67 & $\mathrm{I}=754.67(\mathrm{td})^{-0.67}$ & $\mathrm{R}=1$ \\
50 & 862.38 & 0.67 & $\mathrm{I}=862.38(\mathrm{td})^{-0.67}$ & $\mathrm{R}=1$ \\
100 & 969.5 & 0.67 & $\mathrm{I}=969.5(\mathrm{td})^{-0.67}$ & $\mathrm{R}=1$ \\
\hline
\end{tabular}

Table 6. Rainfall IDF empirical equation for respective return period and their correlation coefficient, $\mathrm{R}$ for Rwamagana District.

In comparing with the value of correlation coefficients $\mathbf{R}$ to those found by [45] in Northern Oueme Valley, Benin Republic (West Africa), [46] in Najran and Hafr Albatin regions in the kingdom of Saudi Arabia (KSA) and [5] in Bangladesh; we were found that the correlation coefficients $\mathbf{R}$ for all the eight stations are the same as their results, ranging between (0.997-1). This indicates that in all cases, the correlation coefficient $\mathrm{R}$ is very high demonstrating the goodness of fit of the equation to establish Intensity-Duration-Frequency curves in Nyabugogo catchment; mean that a correlation coefficient of 1 was found for each equation, which indicates a strong positive relationship in the IDF equation. Similar results have been obtained by [47]. Evaluation of Figure 3 and Figure 4 and Tables 3-6, it shows that the highest rainfall will happen at the first rainfall durations (less than 1h), means that much floods will have occurred in this coming years but the effects of a flood happening in Nyabugogo catchment should be managed when Engineers make attention on these 
results when they were designing flood control and drainage structures in this catchment especially in urban areas. [48-50]; discussed the importance of rainfall IDF curves to flood control for future events.

Finally, the formulation of the new hydraulic structures was done with the consideration of the predicted peak rate of runoff for the whole Nyabugogo catchment. Here Manning equation was compared with the hydrological equation (using a rational method). All hydrological discharges established and carried out at Gitega station were simultaneously done for all seven remaining stations. As shown in (table 7), the predicted $Q_{\operatorname{logy}}$ (peak rate of runoff) was increased with the increase in the rainfall intensities.

As suggested by [13] on the rehabilitation and reconstruction of damaged or clogged drainage systems which cause floods in Nyabugogo catchment, it was found that the predicted peak rate of runoff $\left(\mathrm{Q}_{\log y}\right)$ should be less than the hydraulic discharge $\left(\mathrm{Q}_{\text {lics }}\right)$ to overcome or to manage flooding when Engineers are designing any hydraulic structures in Nyabugogo catchment i.e: $\mathbf{Q}_{\operatorname{logy}}<\mathbf{Q}_{\mathbf{l i c s}}[51,52]$.

Therefore, with the formulation of a formula for calculation on the maximum amount of water that can or should be permitted to pass through a waterway (drainage system) which is the main cause of flooding in Nyabugogo catchment as the prime objective of this study which has not been addressed in previous books and articles, through the design of a hydraulic structure based on peak rate of runoff in this study, the calculation of maximum water intake of a drainage or waterway is now possible. The Frequency factor or runoff Coefficient Adjustment Factor $\left(\mathbf{C}_{\mathbf{f}}\right)$ values that can be used are listed in (Table S6). The product of the Frequency factor $\mathbf{C}_{\mathbf{f}}$ and runoff coefficient $(\mathbf{C})$ shall not exceed 1 means $0<\mathrm{C} \leq 1$. The runoff coefficient $\mathrm{C}$ is the ratio of the peak runoff rate to the rainfall intensity and is dimensionless. The runoff coefficient is defined as: The 
runoff coefficient, $\mathrm{C}$, is an integrated value representing many factors influencing the rainfallrunoff relationship, i.e. Topography, vegetation cover and land use [53]. The coefficient must account for all factors affecting the relation of peak flow to average rainfall intensity other than area and response time. Design values are normally obtained from table S7 of suggested values.

It rarely happens, higher intensity of rainstorms may need a change of the coefficient because infiltration and other losses have a proportionally smaller effect. For adjustment of the Rational Method for use during major rainstorms, this can be done by multiplying the right side of the Rational Formula by a frequency factor $\mathrm{C}_{\mathrm{f}}$. Thus effect. Thus, the rational Formula at this point becomes $\mathbf{Q}_{\mathbf{l o g} \mathbf{y}}=(\mathbf{A R F}) * \mathbf{C}_{\mathbf{f}} * \mathbf{C} * \mathbf{I} * \mathbf{A}$

Finally, by using the data from Tables 3 to 6 and Table S2 to S5, the IDF equation can be derived. Table 7 shows the results of the empirical equation of predicted peak rate of runoff $\left(Q_{\operatorname{logy}}\right)$ using Gumbel distribution and Ration methods respectively. The empirical IDF and The predicted peak rate of runoff $\left(\mathrm{Q}_{\text {logy }}\right)$ equation can be written as seen below:

$$
\begin{aligned}
\mathbf{I} & =\mathbf{X} *(\mathbf{t d})^{-0.67} \\
\mathbf{Q}_{\operatorname{logy}} & =(\mathbf{A R F}) * \mathbf{C}_{\mathbf{f}} * \mathbf{C} *\left(\mathbf{X} *(\mathbf{t d})^{-0.67}\right) * \mathbf{A}
\end{aligned}
$$

Where values of $\mathrm{X}$ and $\mathrm{C}_{\mathrm{f}}$ are found in Table 3 to 6 , Table $\mathrm{S} 2$ to $\mathrm{S} 5$ and Table $\mathrm{S} 6$ respectively.

$\begin{array}{lllll}\text { Return Period } & \mathbf{x} & \mathbf{y} & \text { Equation } & \text { Hydrological discharge equation }\left(Q_{\log }\right)\end{array}$

(Year)

\begin{tabular}{lllll}
\hline 2 & 356.25 & 0.67 & $\mathrm{I}=356.25(\mathrm{td})^{-0.67}$ & $\mathbf{Q}_{\operatorname{logy}}=(\mathbf{A R F}) * \mathbf{C} *\left(\mathbf{3 5 6 . 2 5}(\mathrm{td})^{-0.67}\right) * \mathbf{A}$ \\
5 & 491.13 & 0.67 & $\mathrm{I}=491.13(\mathrm{td})^{-0.67}$ & $\mathbf{Q}_{\operatorname{logy}}=(\mathbf{A R F}) * \mathbf{C} *\left(\mathbf{4 9 1 . 1 3}(\mathrm{td})^{-0.67}\right) * \mathbf{A}$ \\
10 & 580.64 & 0.67 & $\mathrm{I}=580.64(\mathrm{td})^{-0.67}$ & $\mathbf{Q}_{\operatorname{logy}}=(\mathbf{A R F}) * \mathbf{C} *\left(\mathbf{5 8 0 . 6 4}(\mathrm{td})^{-0.67}\right)^{* \mathbf{A}}$
\end{tabular}


25

50

100
693.53

812.46

860.49

\begin{abstract}
0.67
\end{abstract}
$\mathrm{I}=693.53(\mathrm{td})^{-0.67}$

$Q_{\log y}=1.1(A R F) * C *\left(693.53(t d)^{-0.67}\right) * A$

$0.67 \quad \mathrm{I}=812.46(\mathrm{td})^{-0.67}$

$Q_{\log }=1.2(A R F) * C *\left(812.46(t d)^{-0.67}\right) * A$

$$
\left.Q_{\operatorname{logy}}=1.25(A R F) * C *(860.49(t d))^{-0.67}\right) * A
$$

Table 3. The predicted peak rate of runoff $\left(\mathrm{Q}_{\operatorname{logy}}\right)$, equations for Gitega meteorological station (Nyarugenge District).

Frequency Factors for Rational Formula and its Recurrence Interval (years) are found in table S6.

The assumptions associated with the rational method are: If the catchment area increases $\left(>2 \mathrm{~km}^{2}\right)$ the rational formula becomes less accurate [54]. In such a case the point area should be multiplied by ARF (Area Reduction Factor). To deal with this problem, and avoid overestimating flows from larger catchments, areal reduction factors (ARF) have been developed. The expression is valid for the storm durations of 5mins to 48h [55]. Processes used in Gitega station for establishing the predicted peak rate of runoff ( $\mathbf{Q}_{\mathbf{l o g y}}$ ), equations for Gitega meteorological station (Nyarugenge District), are similar to all remaining seven stations such as Kanombe Aero, Kabuye sugar, Rulindo, Byumba Pref, Rwamagana, Kiziguro and Kayonza station. More precisely, this design can be applied to quantify flood and overflow frequencies of the catchment drainage systems and storage equipment and to design adaptation strategies. 


\section{CONCLUSIONS}

This paper highlights insights into how the rainfall can be projected in the Nyabugogo catchment. Since the area of the catchment is big and has diverse climatic conditions that vary from one District to another, a relation for each District had gotten to establish the intensity of the rainfall for different duration and different return periods. These equations show that for a given return period a decrease in rainfall intensity leads to an increase in rainfall duration. We found that the results showed a good correlation between the rainfall intensity calculated by the way used and the values developed by the calibrated equations with a correlation coefficient above 0.987 . This shows that the goodness of fit of the equations to establish Intensity-Duration-Frequency curves in the District's concern for a duration varying from 10-min to 1440-min and return periods of two years to a hundred years.

The rational method estimates the peak rate of runoff at a specific location in a catchment was established. The results show that the peak rate of runoff (hydrological discharge) should be less than hydraulic discharge (Qlics) obtained by using the Manning formula; used for designing hydraulic structures. This will lessen the overflow of water in any designed hydraulic structure. This research will be applied in the designing of hydraulic structures (like culverts and bridges) conservation studies, management of municipal infrastructures and design of safe and economical structural flood control, storage and routing of stormwater, surface drainage and flood plain management. Each District had its presented station in the study. From the research results, the following recommendations have been proposed: Reconstructing the new hydraulic structures due to the incapacity of existing structures of carrying predicted peak discharges; evacuation of residents along the Mpazi channel to avoid flood-related risks and a part of the open channel after the Nyabugogo- Kinamba Bridge be dredged several times to remove all deposed sediments 
transported by the water along the whole channel. This research strongly agrees that ministry of infrastructures, the ministry of environment and the local community should take necessary means or measures to make sure that proper structures (drainage, bridge, house, etc.) are built and clear in the rainfall season. It is also advised that people should avoid constructing new buildings on waterways to reduce the continuing event of flooding and the government must make sure that constructing buildings in flood-prone areas should be stopped.

\section{Supporting Information}

Supplementary data associated with this article can be found in the online version.

\section{Acknowledgments}

This study was funded by the National Natural Science Foundation of China (NSFC: 41772236) and the Science and Technology Department. 


\section{Reference}

1. Mirhosseini, G., Srivastava, P., Stefanova, L.: The impact of climate change on rainfall Intensity-Duration-Frequency (IDF) curves in Alabama. Reg. Environ. Chang. 13, 25-33 (2013). https://doi.org/10.1007/s10113-012-0375-5

2. Koutsoyiannis, D., Kozonis, D., Manetas, A.: intensity-duration-frequency relationships. 206, 118-135 (1998)

3. Norbert, R.J.: DESIGN OF STORM WATER CHANNEL; CASE STUDY: KICUKIRO DISTRICT, KAGARAMA SECTOR. (2019)

4. MIDIMAR: Identification of Disaster Higher Risk Zones on Floods and Landslides in Rwanda Republic of Rwanda Ministry of Disaster Management and Refugee Affairs Unit of Research and Public Awareness Disaster High Risk Zones on. 1-33 (2012)

5. Rasel, M., Hossain, S.M.: Development of Rainfall Intensity Duration Frequency (R-IDF) Equations and Curves for Seven Divisions in Bangladesh. Int. J. Sci. Eng. Res. 6, 96-101 (2015)

6. Mishra, V., Wallace, J.M., Lettenmaier, D.P.: Relationship between hourly extreme precipitation and local air temperature in the United States. Geophys. Res. Lett. 39, 1-7 (2012). https://doi.org/10.1029/2012GL052790

7. Gaume, E., Bain, V., Bernardara, P., Newinger, O., Barbuc, M., Bateman, A., Blaškovičová, L., Blöschl, G., Borga, M., Dumitrescu, A., Daliakopoulos, I., Garcia, J., Irimescu, A., Kohnova, S., Koutroulis, A., Marchi, L., Matreata, S., Medina, V., Preciso, E., Sempere-Torres, D., Stancalie, G., Szolgay, J., Tsanis, I., Velasco, D., Viglione, A.: A 
compilation of data on European flash floods. J. Hydrol. 367, 70-78 (2009). https://doi.org/10.1016/j.jhydrol.2008.12.028

8. Papagiannaki, K., Lagouvardos, K., Kotroni, V., Bezes, A.: Flash flood occurrence and relation to the rainfall hazard in a highly urbanized area. Nat. Hazards Earth Syst. Sci. 15, 1859-1871 (2015). https://doi.org/10.5194/nhess-15-1859-2015

9. Willner, S.N., Levermann, A., Zhao, F., Frieler, K.: Adaptation required to preserve future high-end river flood risk at present levels. Sci. Adv. 4, 1-9 (2018). https://doi.org/10.1126/sciadv.aao1914

10. Hosseinzadehtalaei, P., Tabari, H., Willems, P.: Satellite-based data driven quantification of pluvial floods over Europe under future climatic and socioeconomic changes. Sci. Total Environ. 721, 137688 (2020). https://doi.org/10.1016/j.scitotenv.2020.137688

11. Brammer, H.: Floods in Bangladesh: II. Flood Mitigation and Environmental Aspects. Geogr. J. 156, 158 (1990). https://doi.org/10.2307/635323

12. Frumkin, H., Hess, J., Luber, G., Malilay, J., McGeehin, M.: Climate change: The public health response. Am. J. Public Health. 98, 435-445 (2008). https://doi.org/10.2105/AJPH.2007.119362

13. Munyaneza, O., Nzeyimana, Y.K., Wali, U.G.: Hydraulic structures design for flood control in the Nyabugogo wetland, Rwanda. 8560783, 1-12 (2011)

14. Handmer, J.: Chapter 4 Changes in Impacts of Climate Extremes: Human Systems and Ecosystems. (2012)

15. Abolade, O., Muili, A.B., Ikotun, S.A.: Impacts of flood disaster in Agege local 
government area Lagos , Nigeria. Int. J. Dev. Sustain. 2, 2354-2367 (2013)

16. Nirupama, N., Simonovic, S.P.: Increase of flood risk due to urbanisation: A Canadian example. Nat. Hazards. 40, 25-41 (2007). https://doi.org/10.1007/s11069-006-0003-0

17. Burlando, P., Montanari, A., Rosso, R.: Modelling hydrological data with and without long memory. Meccanica. 31, 87-101 (1996). https://doi.org/10.1007/BF00444157

18. Sane, Y., Panthou, G., Bodian, A., Vischel, T., Lebel, T., Dacosta, H., Quantin, G., Wilcox, C., Ndiaye, O., Diongue-Niang, A., Diop Kane, M.: Intensity-duration-frequency (IDF) rainfall curves in Senegal. Nat. Hazards Earth Syst. Sci. 18, 1849-1866 (2018). https://doi.org/10.5194/nhess-18-1849-2018

19. Robert Manning, (Hydraulic engineer); John Purser Griffith; T F Pigot; Leveson Francis Vernon-Harcourt: On the flow of water in open channels and pipes. (1890)

20. Engineers, W.-M.: Urban storm drainage criteria manual. Denver, Colo. : WrightMcLaughlin Engineers : Distributed by Urban Drainage \& Flood Control District. (1969)

21. Nhat, L., Tachikawa, Y., Takara, K.: Establishment of intensity-duration-frequency curves for precipitation in the monsoon area of Vietnam. Ann. Dis. Prev. Res. Inst. 93-103 (2006)

22. de Paola, F., Giugni, M., Topa, M.E., Bucchignani, E.: Intensity-Duration-Frequency (IDF) rainfall curves, for data series and climate projection in African cities. Springerplus. 3, 1-18 (2014). https://doi.org/10.1186/2193-1801-3-133

23. Kotei, R., Ofori, E., Agyare, W.A.: Establishment of rainfall intensity-duration-frequency (idf) curves for mampong-ashanti municipal area of the Ashanti region in Ghana. ARPN J. 
Eng. Appl. Sci. 8, 693-698 (2013)

24. Van de Vyver, H., Demarée, G.R.: Elaboration des courbes Intensité-Durée-Fréquence (IDF) des précipitations à Lubumbashi, Congo, sous l'hypothèse des données insuffisantes. Hydrol. Sci. J. 55, 555-564 (2010). https://doi.org/10.1080/02626661003747390

25. Nhapi, I.: Assessment of Water Pollution Levels in the Nyabugogo Catchment, Rwanda. Open Environ. Eng. J. 4, 40-53 (2011). https://doi.org/10.2174/1874829501104010040

26. Langousis, A., Veneziano, D.: Intensity-duration-frequency curves from scaling representations of rainfall. Water Resour. Res. 43, 1-12 (2007). https://doi.org/10.1029/2006WR005245

27. Mohymont, B., Demarée, G.R., Faka, D.N.: Establishment of IDF-curves for precipitation in the tropical area of Central Africa - comparison of techniques and results. Nat. Hazards Earth Syst. Sci. 4, 375-387 (2004). https://doi.org/10.5194/nhess-4-375-2004

28. Koutsoyiannis, D.: Statistics of extremes and estimation of extreme rainfall: II. Empirical investigation of long rainfall records. Hydrol. Sci. J. 49, 591-610 (2004). https://doi.org/10.1623/hysj.49.4.591.54424

29. Ghanmi, H., Bargaoui, Z., Mallet, C.: Estimation of intensity-duration-frequency relationships according to the property of scale invariance and regionalization analysis in a Mediterranean coastal area. J. Hydrol. 541, 38-49 (2016). https://doi.org/10.1016/j.jhydrol.2016.07.002

30. Skahill, B.E., AghaKouchak, A., Cheng, L., Byrd, A., Kanney, J.: Bayesian Inference of 
Nonstationary Precipitation Intensity-Duration-Frequency Curves For Infrastructure Design. 20 (2016)

31. Yilmaz, A.G., Imteaz, M.A., Perera, B.J.C.: Investigation of non-stationarity of extreme rainfalls and spatial variability of rainfall intensity-frequency-duration relationships: a case study of Victoria, Australia. Int. J. Climatol. 37, 430-442 (2017). https://doi.org/10.1002/joc.4716

32. Choi, J., Lee, O., Jang, J., Jang, S., Kim, S.: Future intensity-depth-frequency curves estimation in Korea under representative concentration pathway scenarios of Fifth assessment report using scale-invariance method. Int. J. Climatol. 39, 887-900 (2019). https://doi.org/10.1002/joc.5850

33. Lee, S.K., Dang, T.A.: Simulating rainfall IDF curve for flood warnings in the Ca Mau coastal area under the impacts of climate change. Int. J. Clim. Chang. Strateg. Manag. (2020). https://doi.org/10.1108/IJCCSM-06-2020-0067

34. Rashid, M.M., Faruque, S.B., Alam, J.B.: Modeling of Short Duration Rainfall Intensity Duration Frequency (SDR- IDF) Equation for Sylhet City in Bangladesh. ARPN J. Sci. Technol. 2, 92-95 (2012)

35. Haddad, K., Rahman, A.: Design Rainfall Estimation for Short Storm Durations Using LMoments and Generalised Least Squares Regression-Application to Australian Data. Int. J. Water Resour. .... 1, 210-218 (2011)

36. Nissen, K.M., Ulbrich, U.: Increasing frequencies and changing characteristics of heavy precipitation events threatening infrastructure in Europe under climate change. Nat. Hazards Earth Syst. Sci. 17, 1177-1190 (2017). https://doi.org/10.5194/nhess-17-1177- 
2017

37. Borga, M., Vezzani, C., Dall Fontana, G.: Regional rainfall depth-duration-frequency equations for an alpine region. Nat. Hazards. 36, 221-235 (2005). https://doi.org/10.1007/s11069-004-4550-y

38. Porto de Carvalho, J.R., Assad, E.D., de Oliveira, A.F., Silveira Pinto, H.: Annual maximum daily rainfall trends in the midwest, southeast and southern Brazil in the last 71 years. Weather Clim. Extrem. 5, 7-15 (2014). https://doi.org/10.1016/j.wace.2014.10.001

39. Cycle, T.W., Properties, W.: N.t. waterwatch.

40. Davies, E.G.: THE UNIVERSITY OF WESTERN ONTARIO DEPARTMENT OF CIVIL AND Water Resources Research Report An Integrated System Dynamics Model for Analyzing Behaviour of the. 233 (2008)

41. Solaiman, T.A., and Simonovic, S.P.: THE UNIVERSITY OF WESTERN ONTARIO DEPARTMENT OF CIVIL AND Water Resources Research Report Guidelines for Flood Frequency Estimation under Climate Change By: and. (2011)

42. Al Mamun, A., bin Salleh, M.N., Noor, H.M.: Estimation of short-duration rainfall intensity from daily rainfall values in Klang Valley, Malaysia. Appl. Water Sci. 8, 1-10 (2018). https://doi.org/10.1007/s13201-018-0854-z

43. Basumatary, V., Sil, B.: Generation of Rainfall Intensity-Duration-Frequency curves for the Barak River Basin. Meteorol. Hydrol. Water Manag. 6, (2017). https://doi.org/10.26491/mhwm/79175

44. Carlier, E., Khattabi, J. El: Impact of Global Warming on Intensity-Duration-Frequency 
(IDF) Relationship of Precipitation: A Case Study of Toronto, Canada. Open J. Mod. Hydrol. 06, 1-7 (2016). https://doi.org/10.4236/ojmh.2016.61001

45. Agbazo, M., Koton'Gobi, G., Kounouhewa, B., Alamou, E., Afouda, A.: Estimación de las curvas IDF de extrema precipitación por escala simple en el Valle Oueme, al Norte de la República de Benín (Africa occidental). Earth Sci. Res. J. 20, D1-D7 (2016). https://doi.org/10.15446/esrj.v20n1.49405

46. Elsebaie, I.H.: Developing rainfall intensity-duration-frequency relationship for two regions in Saudi Arabia. J. King Saud Univ. - Eng. Sci. 24, 131-140 (2012). https://doi.org/10.1016/j.jksues.2011.06.001

47. Kundwa, M.J.: Development of Rainfall Intensity Duration Frequency (IDF) Curves for Hydraulic Design Aspect. J. Ecol. Nat. Resour. 3, (2019). https://doi.org/10.23880/jenr16000162

48. Syarifudin, A., Destania, H.R.: IDF Curve Patterns for Flood Control of Air Lakitan river of Musi Rawas Regency. IOP Conf. Ser. Earth Environ. Sci. 448, (2020). https://doi.org/10.1088/1755-1315/448/1/012054

49. Agarwal, S., Evaluation, W.: IDF Curve Generation for Historical Rainfall Events. (2020)

50. Jokowinarno, D.: Rainwater Harvesting for Flood Peak Reduction in Way Awi

Catchment, Indonesia. Int. J. GEOMATE. 18, 246-251 (2020).

https://doi.org/10.21660/2020.70.49845

51. Bengtson, H.: Manning Equation for Open Channels.

52. DUDFC: Chapter 6 Runoff. Urban Storm Drain. Criteria Man. Vol. 1. 1, (2016) 
53. Del Giudice, G., Padulano, R., Rasulo, G.: Factors affecting the runoff coefficient. Hydrol. Earth Syst. Sci. Discuss. 9, 4919-4941 (2012). https://doi.org/10.5194/hessd-9-4919-2012

54. Veneziano, D., Langousis, A.: The areal reduction factor: A multifractal analysis. Water Resour. Res. 41, 1-15 (2005). https://doi.org/10.1029/2004WR003765

55. Jaleel, L.A., Maha Atta Farawn: Developing Rainfall Intensity-Duration-. Kufa J. Eng. 5, $105-112(2013)$ 